\title{
Linking place attachment and social interaction: towards meaningful public places
}

\begin{abstract}
ABSTRCT
Purpose : A public space is a place of significance when it fulfils the human need for social interaction and attachment. However, the scarcity of public spaces poses a challenge to support socialisation for people within a defined social and cultural group. The purpose of this paper is to explore the association between place attachment and social interaction within public spaces in the city centre of Kuala Lumpur, Malaysia.

Design/methodology/approach: Face-to-face interviews with urban users were conducted to examine the users' engagement in three main public spaces in the city and the significance of these spaces to everyday social interaction. Field observations were carried out to examine patterns of users' activities and interactions.

Findings: The authors uncover a lack of multi-functional spaces to support diverse forms of interactions in the city. A street has an important function to generate activities. However, spaces for people to sit and stay remain scarce, and are in most cases consumed by extended commercial use and thus considered private. Opportunities for social interaction are very limited. The significance of the places relates strongly to commercial and tourism functions, and hence place attachment evolves around those activities. Participants associated their familiarity and engagement with interaction between familiar people, close ethnic relationships and business acquaintances.
\end{abstract}

Practical implications: The authors argue that more robust and socially responsive public spaces should be reclaimed for the culturally diverse users.

Social implications: Development of attachment through meaningful spaces for people to stay and interact could enhance the role of public spaces in the city.

Originality/value: By understanding the social meanings of places, particularly in a multi-cultural setting, a stronger basis for designing and managing urban places towards resiliency and social sustainability can be provided.

Keyword: Urban design; Social interaction; Public places; Place attachment 